\title{
Article \\ Investigating the Antifungal Mechanism of Action of Polygodial by Phenotypic Screening in Saccharomyces cerevisiae
}

\author{
Purity N. Kipanga ${ }^{1,2,3, *(\mathbb{D}}$, Liesbeth Demuyser ${ }^{3,4}$, Johannes Vrijdag ${ }^{5}\left(\mathbb{D}\right.$, Elja Eskes ${ }^{3,4,6}$, Petra $^{\prime}$ hooge $^{7}$, \\ Josphat Matasyoh ${ }^{8}$, Geert Callewaert ${ }^{7}$, Joris Winderickx ${ }^{6}\left(\mathbb{D}\right.$, Patrick Van Dijck ${ }^{3,4,+}$ and Walter Luyten ${ }^{2,+}+\mathbb{C}$ \\ 1 Faculty of Pharmaceutical Sciences, KU Leuven, 3000 Leuven, Belgium \\ 2 Department of Biology, Animal Physiology and Neurobiology, KU Leuven, 3000 Leuven, Belgium; \\ walter.luyten@kuleuven.be \\ 3 Laboratory of Molecular Cell Biology, Department of Biology, KU Leuven, 3000 Leuven, Belgium; \\ liesbeth.demuyser@kuleuven.be (L.D.); elja.eskes@kuleuven.be (E.E.); patrick.vandijck@kuleuven.be (P.V.D.) \\ 4 VIB-KU Leuven Center for Microbiology, 3000 Leuven, Belgium \\ 5 Department of Chemistry, Molecular Design and Synthesis, KU Leuven, 3000 Leuven, Belgium; \\ Johannes.Vrijdag@martens.be \\ 6 Department of Biology, Functional Biology, KU Leuven, 3000 Leuven, Belgium; joris.winderickx@kuleuven.be \\ 7 The Yeast Hub Lab, KU Leuven, Campus Kulak, 8500 Kortrijk, Belgium; petra.dhooge@kuleuven.be (P.D.); \\ geert.callewaert@kuleuven.be (G.C.) \\ 8 Department of Chemistry, Egerton University, Njoro 20107, Kenya; jmatasyoh@egerton.ac.ke \\ * Correspondence: nmercileen@gmail.com \\ $+\quad$ W.L. and P.V.D. are joint senior authors.
}

\section{check for} updates

Citation: Kipanga, P.N.; Demuyser, L.; Vrijdag, J.; Eskes, E.; D’hooge, P.; Matasyoh, J.; Callewaert, G.;

Winderickx, J.; Van Dijck, P.; Luyten, W. Investigating the Antifungal Mechanism of Action of Polygodial by Phenotypic Screening in Saccharomyces cerevisiae. Int. J. Mol. Sci. 2021, 22, 5756. https://doi.org/ $10.3390 /$ ijms 22115756

Academic Editor: Toshio Morikawa

Received: 20 April 2021

Accepted: 25 May 2021

Published: 28 May 2021

Publisher's Note: MDPI stays neutral with regard to jurisdictional claims in published maps and institutional affiliations.

Copyright: (c) 2021 by the authors. Licensee MDPI, Basel, Switzerland. This article is an open access article distributed under the terms and conditions of the Creative Commons Attribution (CC BY) license (https:// creativecommons.org/licenses/by/ $4.0 /)$.

\begin{abstract}
Polygodial is a "hot" peppery-tasting sesquiterpenoid that was first described for its anti-feedant activity against African armyworms. Using the haploid deletion mutant library of Saccharomyces cerevisiae, a genome-wide mutant screen was performed to shed more light on polygodial's antifungal mechanism of action. We identified 66 deletion strains that were hypersensitive and 47 that were highly resistant to polygodial treatment. Among the hypersensitive strains, an enrichment was found for genes required for vacuolar acidification, amino acid biosynthesis, nucleosome mobilization, the transcription mediator complex, autophagy and vesicular trafficking, while the resistant strains were enriched for genes encoding cytoskeleton-binding proteins, ribosomal proteins, mitochondrial matrix proteins, components of the heme activator protein (HAP) complex, and known regulators of the target of rapamycin complex 1 (TORC1) signaling. WE confirm that polygodial triggers a dose-dependent vacuolar alkalinization and that it increases $\mathrm{Ca}^{2+}$ influx and inhibits glucose-induced $\mathrm{Ca}^{2+}$ signaling. Moreover, we provide evidence suggesting that TORC1 signaling and its protective agent ubiquitin play a central role in polygodial resistance, suggesting that they can be targeted by polygodial either directly or via altered $\mathrm{Ca}^{2+}$ homeostasis.
\end{abstract}

Keywords: Polygodial; antifungal; Saccharomyces cerevisiae; haploid deletion mutant library; V-ATPase; vacuolar $\mathrm{pH}$; ubiquitin; TORC1 signaling; $\mathrm{Ca}^{2+}$ signaling and $\mathrm{Ca}^{2+}$ homeostasis

\section{Introduction}

Apart from the anti-feedant activity against a number of pests [1-3], polygodial (Figure 1) has been reported to possess biological activities such as antifungal [4-6], antibacterial [7], anti-tumor [8], larvicidal [9], antihelminthic [10], antifouling [11], antiinflammatory [12], analgesic [13], antitrypanosomal, and antileishmanial activities [14]. As a bioactive constituent, it is produced in several plants of the Canellaceae [1], Polygonaceae [15], and Winteraceae [16] families, as well as in marine animals such as sponges and molluscs [17,18]. Recently, we isolated polygodial from Warburgia ugandensis Sprague subspecies ugandensis (Canellaceae) and showed its activity against Candida albicans [6]. Specifically, we showed that low concentrations of polygodial are not only active against the planktonic forms of $C$. albicans, but that the compound is also active against its biofilm 
forms (biofilm inhibiting concentration: $\mathrm{BIC}_{50}=10.8 \pm 5 \mu \mathrm{g} / \mathrm{mL}$ ); which are a major menace to public health due to their increased resistance to currently available antifungals [19]. These interesting findings prompted us to elucidate the antifungal mechanism of action (MOA) of polygodial.<smiles>CC1(C)CCC[C@]2(C)[C@@H](C=O)C(C=O)=CC[C@]12C</smiles>

Figure 1. The chemical structure of polygodial.

Earlier antifungal MOA studies have led to different conclusions. Taniguchi and colleagues showed that polygodial disrupted the cell membrane in S. cerevisiae, resulting in loss of cellular content [20]. Although these authors also showed that polygodial inhibited both respiration and the synthesis of cellular macromolecules such as DNA, RNA, proteins, and polysaccharides, they concluded that these were likely secondary effects of the cell damage caused by polygodial since the inhibition of these macromolecules was not specific. In addition, they also ruled out the mitochondria as the primary target since only exogenous respiration and not endogenous respiration was affected. Later, Lunde and Kubo intimated a more complex mechanism of polygodial's activity [21]. Specifically, they showed, using isolated membrane fractions of S. cerevisiae, that polygodial rapidly inhibited mitochondrial ATPase at similar concentrations $(3.5 \mu \mathrm{g} / \mathrm{mL})$ as its minimum fungicidal concentration. Polygodial also showed a low inhibitory activity against the vacuolar (V-)ATPase. Further, they observed that while cytoplasmic petite mutants that lack mitochondrial DNA $\left(r h o^{-}\right)$and respiratory-deficient petite mutants $\left(r h o^{0}\right)$ were resistant to polygodial at $6.25 \mu \mathrm{g} / \mathrm{mL}$, the wild type (WT) was sensitive to this concentration. They thus concluded that polygodial's major target was the mitochondrial ATPase, whose inhibition results in low cellular ATP production, explaining polygodial's fungicidal activity. Castelli's group [22] argued that a more significant effect of polygodial was the uncoupling of ATP synthesis from the electron transport and not the direct inhibition of the mitochondrial ATPase. Other authors have suggested targets of polygodial such as the plasma membrane $\mathrm{H}^{+}$-ATPase [23], cellular glutathione [24], and the vacuolar membrane [25].

We explored the antifungal MOA of polygodial on C. albicans using a genome-wide growth-based screening of the haploid deletion strain library of $S$. cerevisiae [26,27]. $S$. cerevisiae was selected as a model organism for a number of reasons, some of which are its similarities to C. albicans (e.g. many features of pathogenic fungi such as biofilm formation, maturation, and drug resistance are conserved in S. cerevisiae) and the availability of complete genomic libraries; which are absent for C. albicans, that facilitate genome-wide screening studies [28,29]. Such a screen of a strain library in the presence of a bioactive compound can provide important functional information based on the scoring of these strains for hypersensitivity and resistance to antifungal compounds. We show that the vacuolar ATPase is involved in buffering the cell against a polygodial insult and discuss the interesting link between the cytoskeletal proteins and the V-ATPases. Finally, we propose that the target for polygodial may act on TORC1 signaling, either directly or via disturbance of the $\mathrm{Ca}^{2+}$ homeostasis.

\section{Results}

\subsection{Phenotypic Screening of Mutants Treated with Polygodial}

We tested the effect of polygodial on the growth of 4828 deletion mutants in the S. cerevisiae haploid MAT $\alpha$ (BY4742) deletion library. Two concentrations of polygodial ( 2 and $6 \mu \mathrm{g} / \mathrm{mL}$ ) were used to select the strains that were either sensitive or resistant to 
polygodial by comparing their growth with that of the wild type (WT) strain S. cerevisiae BY4742 and ranking this growth as described in Section 4.1. From this phenotypic screening, we identified 233 strains displaying polygodial resistance and 135 strains that were polygodial-sensitive. Of these, 47 strains were classified as hyper-resistant (ranked as 6) and 66 strains as hypersensitive (ranked as 0 or 1 ) to polygodial. A representation of how the screening was performed and how growth was used as a read-out to enable ranking is shown in the supplemental Figure S1. We used the Saccharomyces Genome Database (SGD) [30] gene ontology (GO) Term Finder and the functional specification (FunSpec) software [31] as well as manually retrieving information of annotated genes from SGD to classify the strains into groups based on the functional roles, biochemical properties, and localization of their deleted genes (Tables S1 and S2). Next, we used the search tool for the retrieval of interacting genes/proteins (STRING) [32] database to determine the connections between the different encoded gene functions based on physical and genetic interactions, predicted interactions, co-expression, or protein homology. A visualization of the network obtained for the 47 hyper-resistant and 66 hypersensitive gene functions is shown in Figure 2. The networks derived from all retrieved sensitive or resistant gene functions is given in Figures S2 and S3.

A

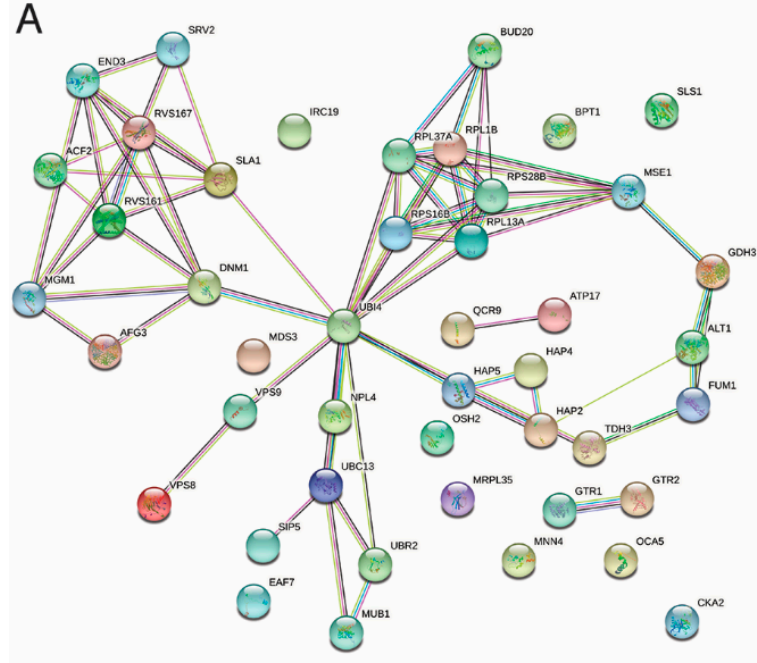

B

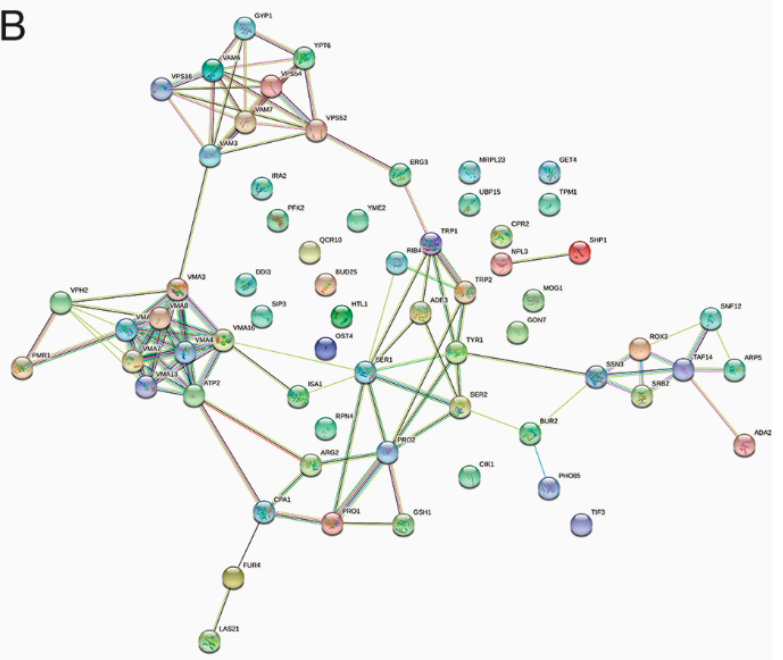

Figure 2. A clustering visualization of the 47 polygodial hyper-resistant (A) and 66 polygodial hypersensitive (B) strains using the STRING database. The colored circular nodes represent proteins while the edges joining the nodes represent protein-protein interactions, either established or predicted interactions.

The cluster and gene enrichment analysis for the hyper-resistant genes (Figure 2A) pointed towards cytoskeleton reorganization and endocytosis, the assembly of ribosome subunits and translation, respiratory gene expression mediated by the HAP complex, and protein ubiquitination and degradation as important processes. In fact, the cluster analysis indicated the latter to play a central role given that the gene UBI4, which encodes ubiquitin, defines a central node that connects to all of the other processes. In addition, the enrichment analysis also retrieved three components that constitute the GSE/EGO complex. This complex is localized at late endosomes and the vacuolar membrane where it serves to sense amino acids, activate TORC1 [33]; a central regulator of cell growth and signal to sort the general amino acid permease Gap1 to the plasma membrane when amino acids become limiting $[34,35]$. Interestingly, also Pib2 was retrieved among the polygodial resistant strains. This protein is a glutamine sensor that acts independently of the GSE/EGO complex to activate TORC1 [36]. Compelling, TORC1 has been linked to endocytosis [37], ribosome biogenesis [38], and the HAP complex [39,40] and therefore TORC1 may represent a second central node in polygodial resistance. The TORC1 node is closely linked to the UBI4 node since ubiquitin was shown to exert a positive effect on TORC1 by preventing 
degradation of the TORC1 subunit Kog1 under stress conditions [41,42]. Thus, since both deletion of UBI4 and abrogation of TORC1 signaling trigger polygodial hyper-resistance, the data of this analysis suggest that both could be the actual targets of polygodial.

For the hypersensitive gene functions (Figure 2B), four main clusters can be seen in the network. These are formed by components of the vacuolar V-ATPase, components required for amino acid biosynthesis, components involved in nucleosome mobilization or the formation of the mediator complex that is required for transcription initiation, as well as components involved in endosome trafficking. Not surprisingly, these components are also specifically enriched when analyzing the pool of polygodial sensitive genes using the FunSpec software as shown in Table 1. The data suggest that cells want to enhance these processes to counteract the effect of polygodial treatment, but that failure to do so results in polygodial sensitivity.

Table 1. Analysis of gene enrichment in the pools of polygodial sensitive and resistant strains based on the FunSpec software. Genes shown in bold correspond to hypersensitive or hyper-resistant strains. K denotes the number of genes from the input (sensitive or resistant strains) in a given GO category, while F refers to the total number of genes encoded by the yeast genome in a given GO category.

\begin{tabular}{|c|c|c|c|}
\hline \multicolumn{4}{|c|}{ Polygodial Sensitive } \\
\hline Process & Genes in Cluster & $\mathbf{K}$ & $\mathbf{F}$ \\
\hline ATP hydrolysis coupled proton transport & VMA1 VMA3 VMA8 VMA7 VMA16 АTP2 VMA4 VMA13 & 8 & 17 \\
\hline vacuolar acidification & VMA1 VMA3 VMA8 VMA7 VMA16 VPH2 VMA4 VMA13 & 8 & 26 \\
\hline piecemeal microautophagy of nucleus & SHP1 ATG8 ATG12 VAM6 VAM7 ATG10 VAM3 ATG13 & 8 & 33 \\
\hline cellular amino acid biosynthetic process & $\begin{array}{c}\text { TYR1 TRP1 PRO1 TRP2 TRP5 ADE3 SER2 ARG2 SER1 CPA1 } \\
\text { PRO2 }\end{array}$ & 11 & 98 \\
\hline nucleosome mobilization & SNF6 SWI3 ARP5 SNF12 TAF14 & 5 & 16 \\
\hline transcription mediator complex & ROX3 MED2 SRB5 SRB2 CSE2 GAL11 SSN3 TAF14 & 8 & 26 \\
\hline $\begin{array}{l}\text { regulation of transcription, } \\
\text { DNA-dependent }\end{array}$ & $\begin{array}{c}\text { ROX3 HTL1 TUP1 MED2 RPN4 SAC3 UME6 EAF1 ADA2 } \\
\text { RTF1 SRB5 SMI1 SNF6 SRB2 SWI3GON7 BUR2 CHS5 ARP5 } \\
\text { CSE2 SNF12 GAL11 ULS1 SSN3 TAF14 }\end{array}$ & 25 & 507 \\
\hline retrograde transport, endosome to Golgi & RGP1 VPS35 VPS52 VPS54 YPT6 & 5 & 18 \\
\hline \multicolumn{4}{|c|}{ Polygodial Resistant } \\
\hline Process & Genes in Cluster & $\mathbf{K}$ & $\mathbf{F}$ \\
\hline CCAAT-binding factor complex & НАР2 НАР4 НАР5 & 3 & 4 \\
\hline GSE/EGO complex & GTR1 GTR2 LTV1 & 3 & 5 \\
\hline cytoskeletal protein binding & SLA1 RVS161 RVS167 SRV2 & 4 & 7 \\
\hline structural constituent of ribosome & $\begin{array}{c}\text { RPL1B RPS1B RPL13A RPS16A RPS16B RPL16A RPS17B } \\
\text { RPL19A RPL41B RPL27B RPL23A RPL23B RPL24A RPL24B } \\
\text { RPS25A RPS28B RPL29 RPS30A RPL37A RPP2A MRPL35 } \\
\text { MRPL38 RSM27 }\end{array}$ & 23 & 218 \\
\hline mitochondrial matrix & $\begin{array}{c}\text { MSK1 MTF2 MSE1 TUF1 CPR3 MDJ1 FUM1 PDX1 CIT1 ALT1 } \\
\text { AAT1 ACO1 SDH5 }\end{array}$ & 13 & 111 \\
\hline
\end{tabular}

\subsection{Vacuolar $p H$ Measurements in the Presence of Polygodial}

The vacuolar membrane ATPase $(V M A)$ genes were highly enriched in the hypersensitive mutants (Table 1). Since the vacuolar ATPase is involved in vacuolar acidification, we examined whether and how polygodial affects vacuolar $\mathrm{pH}$ by measuring vacuolar $\mathrm{pH}$ in polygodial-treated WT S. cerevisiae (Figure 3). We observed that vacuolar $\mathrm{pH}$ values increased dose-dependently with higher concentrations of polygodial, implying that polygodial increases vacuolar $\mathrm{pH}$. Continuous exposure to high concentrations of polygodial can thus disrupt the normal functioning of the vacuole. 
BY4742 S. cerevisiae treated with polygodial

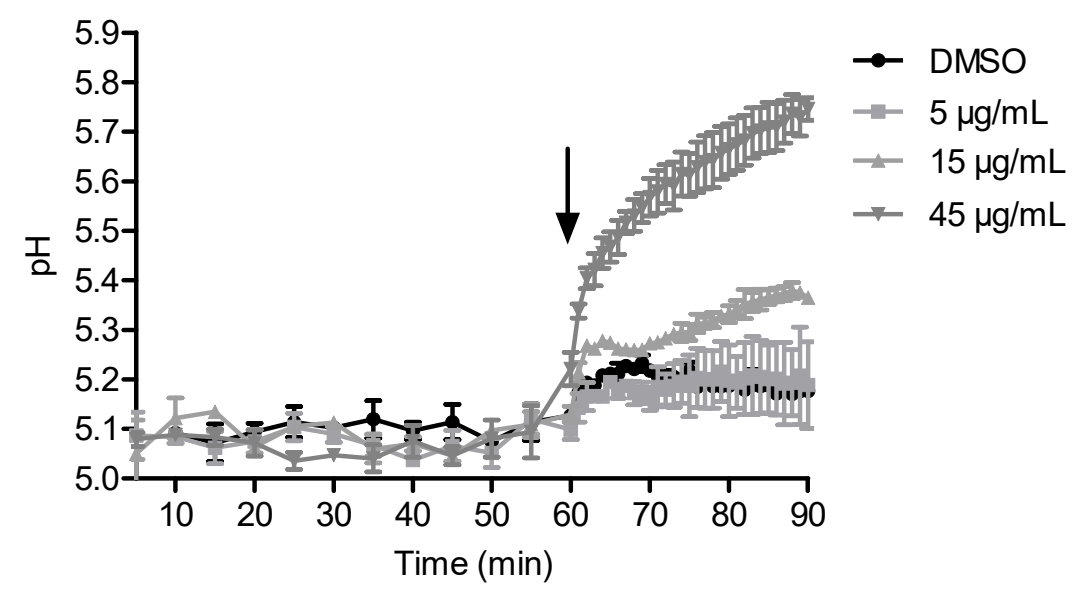

Figure 3. Vacuolar $\mathrm{pH}$ measurements in S. cerevisiae WT in the presence of the vehicle (DMSO) or 5,15 , and $45 \mu \mathrm{g} / \mathrm{mL}$ polygodial, mean with standard error of the mean (SEM), $n=2$. Baseline measurements were first taken for $1 \mathrm{~h}$ in the presence of calibration buffers, then polygodial and DMSO were added in their respective wells, and the plate was further measured for $30 \mathrm{~min}$. The arrow indicates addition of polygodial shortly after $60 \mathrm{~min}$.

\subsection{Effects of Polygodial on Yeast $\mathrm{Ca}^{2+}$ Homeostasis}

It is well established that $\mathrm{pH}$ homeostasis, vacuolar functioning and $\mathrm{Ca}^{2+}$ signaling are closely linked in yeast $[43,44]$. Because extracellular $\mathrm{Ca}^{2+}$ may exert a protective effect against the membrane-damaging action of polygodial [45] and because $\mathrm{Ca}^{2+}$ was shown to act as an important second messenger for TORC1 activation [46,47], we were interested in determining the influence of polygodial on intracellular $\mathrm{Ca}^{2+}$ homeostasis. For this purpose, carbohydrate-starved BY4741 yeast cells were challenged by glucose re-addition in aequorin-based experiments. Glucose re-addition to starved yeast cells has been shown to produce a transient elevation in calcium concentration (TECC) response that is dependent on $\mathrm{Ca}^{2+}$ influx [48].

As shown in Figure 4, in control (DMSO vehicle treated) cells, addition of $10 \mathrm{mM}$ external $\mathrm{Ca}^{2+}$ induced a rapid small $\left[\mathrm{Ca}^{2+}\right]_{\text {cyt }}$ increase and glucose re-addition $(80 \mathrm{mM})$ generated a characteristic TECC response as observed previously [49]. Membrane permeabilization after the TECC response induced a small $\mathrm{Ca}^{2+}$ transient, reflecting the release of $\mathrm{Ca}^{2+}$ mainly sequestered in the vacuole and Golgi during the TECC response [49]. A $30 \mathrm{~min}$ pre-treatment with $10 \mu \mathrm{g} / \mathrm{mL}$ polygodial had no significant effect on baseline $\mathrm{Ca}^{2+}$ levels but cytosolic $\mathrm{Ca}^{2+}$ responses following $10 \mathrm{mM}$ external $\mathrm{Ca}^{2+}$ addition or glucose re-addition increased significantly compared to control cells. In addition, the $\mathrm{Ca}^{2+}$ transient following membrane permeabilization displayed about 4 -fold higher peak. This finding suggests that $\mathrm{Ca}^{2+}$ sequestration is not compromised but that increased $\mathrm{Ca}^{2+}$ influx may underlie the observed $\mathrm{Ca}^{2+}$ changes in polygodial-treated cells. Thirty minute pre-treatment with $25 \mu \mathrm{g} / \mathrm{mL}$ polygodial also caused a significant increase in $\mathrm{Ca}^{2+}$ responses compared to control cells but TECC responses were clearly suppressed compared to cells pre-treated with $10 \mu \mathrm{g} / \mathrm{mL}$. This suggests that apart from increasing $\mathrm{Ca}^{2+}$ influx, polygodial may also disrupt (affect) components of glucose signaling at high concentration. The finding that, at $50 \mu \mathrm{g} / \mathrm{mL}$, polygodial TECC responses were completely inhibited, supports this hypothesis. In addition, at $50 \mu \mathrm{g} / \mathrm{mL}$ polygodial baseline, $\mathrm{Ca}^{2+}$ values were increased but the $\mathrm{Ca}^{2+}$ transient following membrane permeabilization was not affected compared to cells pre-treated with 10 or $25 \mu \mathrm{g} / \mathrm{mL}$ polygodial. 

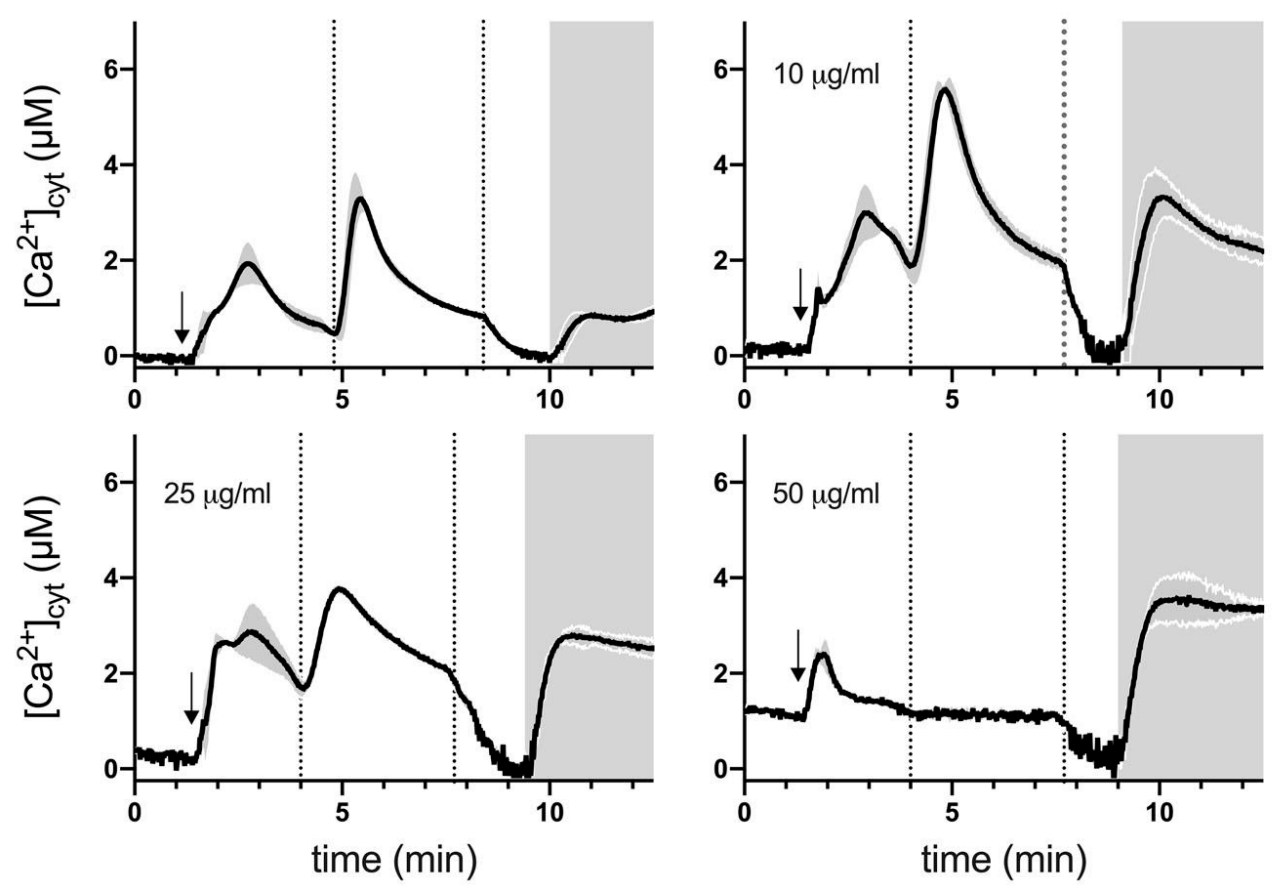

Figure 4. Effects of polygodial on yeast $\mathrm{Ca}^{2+}$ homeostasis. Averaged $\mathrm{Ca}^{2+}$ transient (grey shaded region either side of the $\mathrm{Ca}^{2+}$ transient trajectory marks SEM, $n=3$ ) of wild-type BY4741 yeast cells after $30 \mathrm{~min}$ pre-treatment with vehicle (DMSO) (upper left panel) or 10, 25, and $50 \mu \mathrm{g} / \mathrm{mL}$ polygodial (as indicated). Cells were initially perfused with $\mathrm{Ca}^{2+}$-free starvation medium and then transferred to a $10 \mathrm{mM}$ external $\mathrm{Ca}^{2+}$ medium (indicated by arrow) followed by re-addition of $80 \mathrm{mM}$ glucose (dashed vertical lines indicate perfusion with glucose that results in a TECC response). Thereafter, cells were briefly exposed to $\mathrm{Ca}^{2+}$-free medium prior to membrane permeabilization using Triton X-100 (grey shaded zone correlates with membrane permeabilization).

\section{Discussion}

A chemogenomic screen examines a drug's MOA by measuring the effect of the drug treatment on a collection of genetically distinct strains. According to Parsons et al., gene deletions that render strains hypersensitive to a drug facilitate the identification of pathways and proteins that buffer the cells against toxic effects of the drug, providing clues into its mode of action [50]. On the other hand, in a chemical-genetic interaction where the target gene of a compound is deleted, resistant phenotypes emerge as the target (gene product) to be affected by the compound. This is normally illustrated by screening with higher compound concentrations than the $\mathrm{IC}_{50}$ of the compound on the WT strain. Combining individual drug-mutant relationships (i.e., resistance or sensitivity) into a profile provides a genome-wide view of a compound's effect on the cell [51].

To determine the antifungal MOA of polygodial, the model organism S. cerevisiae was used [28]. We obtained two sets of drug-dependent phenotypes: i.e., hypersensitive and resistant strains, using 2 and $6 \mu \mathrm{g} / \mathrm{mL}$ polygodial, respectively. In the hypersensitive group, vacuolar V-ATPase-related processes such as ATP hydrolysis-coupled proton transport, vacuolar acidification, and proton homeostasis were highly enriched (Table 1). These processes are critical for intracellular cytosolic and vacuolar $\mathrm{pH}$ regulation, and consequently, organellar acidification, in both S. cerevisiae and C. albicans [52,53]. Organellar acidification has been implicated in stress response, protein sorting in the biosynthetic and endocytic pathways, chitin localization, proteolytic activation of zymogen precursors, degradative (autophagic) processes carried out by the vacuole, storage of certain small molecules like $\mathrm{Ca}^{2+}$, and osmoregulation, in both S. cerevisiae and C. albicans [54-56]. In accordance with these stated functions, we also observed enrichment of hypersensitive mutants whose missing genes are responsible for protein sorting and recycling (Figure 2B and Table S1). Kondo et al. [25] concluded from their biochemical and growth inhibition study that the 
vacuolar membrane (on which the V-ATPase resides) is the primary target of polygodial. While it is clear that the vacuole is affected by polygodial treatment, our genomic screen shows that, in the absence of V-ATPase genes, the cells have a poor outcome when exposed to polygodial, rather than showing resistance as expected if the V-ATPase were the direct target. Thus, the vacuole regulates and buffers the cells against toxic effects of polygodial. From our results, it is highly likely that the distorted vacuoles seen by Kondo and colleagues are a secondary effect of polygodial.

Polygodial treatment clearly affected yeast $\mathrm{Ca}^{2+}$ homeostasis (Figure 4). At $10 \mu \mathrm{g} / \mathrm{mL}$, polygodial increased $\mathrm{Ca}^{2+}$ transients associated with addition of external $\mathrm{Ca}^{2+}$, re-addition of glucose (TECC response), and membrane permeabilization while in $\mathrm{Ca}^{2+}$-free medium supplemented with ethylene glycol tetraacetic acid (EGTA), cytosolic $\mathrm{Ca}^{2+}$ returned to baseline levels. Together, these results indicate that polygodial induces a rapid and sustained $\mathrm{Ca}^{2+}$ influx across the plasma membrane, leading to enhanced organellar $\mathrm{Ca}^{2+}$ storage. These findings are, therefore, compatible with the idea that polygodial mainly acts as a surfactant, disrupting plasma membrane lipid-protein interactions. At $25 \mu \mathrm{g} / \mathrm{mL}$ polygodial $\mathrm{Ca}^{2+}$ transients associated with external $\mathrm{Ca}^{2+}$ addition or membrane permeabilization remained elevated, however, TECC responses displayed lower peak and slower recovery. Finally, at $50 \mu \mathrm{g} / \mathrm{mL}$, TECC responses were fully suppressed and basal $\mathrm{Ca}^{2+}$ levels increased. These results therefore suggest that at concentrations $>10 \mu \mathrm{g} / \mathrm{mL}$, polygodial may not only modulate $\mathrm{Ca}^{2+}$ homeostasis but also target glucose and TORC1 signaling.

From the resistant mutants, we could define several processes that contribute to the resistant phenotype. These include cytoskeleton reorganization and endocytosis, the assembly of ribosome subunits and translation, respiratory gene expression mediated by the HAP complex, protein ubiquitination, and TORC1 signaling. The actin cytoskeleton not only acts as a structural scaffolding in the cell, thereby determining the size, shape, and mechanical properties of the cell, but also functions in endocytosis, exocytosis, polarized cell growth, cytokinesis, cell motility, and translation [57]. There are several observations that link the actin cytoskeleton to the V-ATPase. For instance, mutations in the gene encoding the stator V-ATPase E subunit (Vma4p) in S. cerevisiae have been shown to cause changes in cell morphology and cytoskeletal actin, probably mediated by intracellular $\mathrm{pH}$ or $\mathrm{Ca}^{2+}$ changes [58]. Moreover, Zhang and coworkers noticed that at high $\mathrm{pH}$, abnormal bud morphologies and delocalization of actin and chitin occur [59]. Taken together, these data indicate that disruption of the cytoskeletal architecture due to polygodial can have a direct negative effect on the V-ATPase, the vacuole, and other cellular functions.

The HAP complex consists of 4 proteins: Hap2p, Hap3p, Hap4p, and Hap5p, which positively control the expression of genes involved in mitochondrial respiration, mitochondrial function and biogenesis, and mitochondrial translation. Specifically, the HAP complex controls the complete TCA cycle, the electron transport chain, and related pathways [60]. Both the group of Castelli [22] and Lunde and Kubo [21] proposed mitochondria i.e., the electron transport chain and mitochondrial ATPase, respectively, as a target of polygodial. Buschlen et al. [60] indicated that the aforementioned components are part of the 5 respiratory chain complexes of $S$. cerevisiae. It is thus likely that the HAP complex plays a key role in polygodial resistance by controlling cellular respiration. Moreover, the HAP complex senses cellular redox status [61], which is affected by polygodial [24].

Most importantly, our analysis of the resistant mutants identified ubiquitin and TORC1 signaling as central nodes linking several of the aforementioned processes. Indeed, apart from the regulatory links already mentioned above with endocytosis, ribosome biogenesis, the HAP complex, and $\mathrm{Ca}^{2+}$ signaling, both ubiquitin and TORC1 are known to impact vacuole functioning and vacuolar biogenesis [62]. Moreover, TORC1 inhibition is associated to enhanced V-ATPase assembly [63] and the upregulation of autophagy [64], both processes that when failing lead to polygodial sensitivity. In addition, downregulation of TORC1 is associated with an enhanced oxidative phosphorylation (OXPHOS) density and respiration uncoupling [65-67], a mechanism that was previously proposed to underlie the effect of polygodial [22]. Hence, we propose that TORC1 and its protective agent 
ubiquitin may be central targets in the MOA of polygodial. Whether this is a direct effect or mediated by the second messenger $\mathrm{Ca}^{2+}$ remains to be clarified.

In conclusion, we have shown that the vacuolar ATPase is involved in the antifungal action of polygodial in the model system $S$. cerevisiae by buffering the cell against a polygodial insult. The initial evidence from the vacuolar $\mathrm{pH}$ experiments and $\mathrm{Ca}^{2+}$ measurements implicate polygodial further as affecting this organelle. The cytoskeletal proteins have emerged as an interesting link to the vacuolar V-ATPases. Their role as a possible target of polygodial remains to be confirmed. We propose that the target for polygodial may act on TORC1 signaling, either directly or via disturbance of the $\mathrm{Ca}^{2+}$ homeostasis. In essence, our genetic screen has further increased the understanding of polygodial's MOA and has shed light on underlying mechanisms and connections to previously reported observations. Finally, although we used S. cerevisiae to infer polygodial's MOA in C. albicans since the two share about two-thirds of their open reading frames [29], further studies in C. albicans (e.g., using the CRISPR-Cas9 system) are needed to confirm these observations in pathogenic fungi.

\section{Materials and Methods}

\subsection{Chemical Genetic Screen}

The S. cerevisiae haploid MAT $\alpha$ (BY4742) deletion library, consisting of 4828 deletion mutants each lacking one specific gene, was used to determine genes that may be involved in the MOA of polygodial. Using a pinner, the strains stored in $20 \%$ glycerol and YP broth in 96-well plates at $-80{ }^{\circ} \mathrm{C}$ were transferred to YPD-containing microtiter plates and incubated at $30^{\circ} \mathrm{C}$ for 2 days. The strains were then diluted (1:20) and spotted on agar medium containing polygodial and incubated at $30^{\circ} \mathrm{C}$ for 2 days. Throughout the screening process, we used minimal synthetic medium (SD) containing $0.5 \%$ ammonium sulfate and $0.17 \%$ Difco yeast nitrogen base without amino acids, supplemented with $2 \%$ glucose and histidine, lysine, leucine, and uracil (henceforth called $\left.\mathrm{SD}_{\mathrm{HLLU}}\right)$. The amino acid concentrations used are as recommended by Sherman [68]. The $\mathrm{pH}$ was adjusted to 5.5 when $\mathrm{SD}_{\mathrm{HLLU}}$ broth was used. In the $\mathrm{SD}_{\mathrm{HLLU}}$ agar medium (pH 6.5), two concentrations of polygodial, which had previously been established via pilot experiments (i.e., 2 and $6 \mu \mathrm{g} / \mathrm{mL}$ ), were used to screen for hypersensitive and resistant strains, respectively, using growth as read-out. The WT strain (S. cerevisiae BY4742) was also spotted on each plate as a control. An empirical qualitative score from 0 to 6 was used to grade growth (reduced colony formation) in comparison to the WT strain: $0=$ no growth, $1=$ limited growth, 2 = moderate growth, 3 = similar growth as WT, $4=$ slightly more growth than WT, $5=$ denser growth than WT, and $6=$ excellent growth compared to WT.

We used SGD GO Term Finder and FunSpec for the evaluation of groups of genes and proteins (e.g., co-regulated genes, protein complexes, genetic interactors) as defined by their annotation: e.g., functional roles, biochemical properties, or localization. FunSpec uses different databases, other online knowledge bases, and published datasets such as the Gene Ontology and Munich Information Center for Protein Sequences (MIPS) database. These are comprehensive genome databases that list functional classification, known protein complexes, protein classes, mutant phenotypes, and subcellular localization. The Bonferroni-correction used during analysis divides the $\mathrm{p}$-value threshold that would be deemed significant for an individual test, by the number of tests conducted, and thus accounts for spurious significance due to multiple testing over the categories of a database. Additionally, the STRING database was used to visualize protein-protein interactions.

\subsection{Calcium Measurements Using an Apoaequorin System}

The measurements were based on the method described by D'hooge et al. [49]. Briefly, S. cerevisiae BY4741 (MATa his3 $\Delta 1$ leu2 $\Delta 0$ met $15 \Delta 0$ ura3 $\Delta 0$ ) cells were transformed with the plasmid (pYX212-cytAEQ) containing the apoaequorin gene, and transformants were selected for growth on SD medium with $2 \%$ glucose, lacking leucine. Cells were then grown overnight at $30{ }^{\circ} \mathrm{C}$ and harvested when the $\mathrm{OD}_{600}$ reached 2. The yeast cells 
were then immobilized for $1 \mathrm{~h}$ on concanavalin A-coated coverslips in 12-well culture plates in fresh SD medium with $2 \%$ glucose, lacking leucine. Later, when the medium was removed, the cells were washed with $0.1 \mathrm{M} 2-(\mathrm{N}$-morpholino) ethanesulphonic acid (MES) and incubated again for $1 \mathrm{~h}$ at $30^{\circ} \mathrm{C}$ in $0.1 \mathrm{M}$ MES/ trisaminomethane (TRIS) $\mathrm{pH}$ 6.5 supplemented with $5 \mu \mathrm{M}$ coelenterazine (Promega) to charge aequorin. Polygodial was added at final concentrations of 10, 25, and $50 \mu \mathrm{g} / \mathrm{mL}$ for $30 \mathrm{~min}$. Excess coelenterazine was removed by washing the cells. The coverslips were mounted in a thermostated superfusion chamber $\left(30{ }^{\circ} \mathrm{C}\right)$. The glucose-starved yeast cells were initially superfused with $0.1 \mathrm{M}$ MES/TRIS (0-1 min), pH 6.5, followed by 0.1 M MES/TRIS pH 6.5 supplemented with $10 \mathrm{mM} \mathrm{CaCl}_{2}$ (referred to as $\mathrm{Ca}^{2+}$ pulse) from 1-3 min. Cells were then stimulated by the addition of $80 \mathrm{mM}$ glucose (3-7 min) to induce a transient elevation of cytosolic $\mathrm{Ca}^{2+}$ (TECC) response. To estimate intracellular $\mathrm{Ca}^{2+}$ storage from organelles, cells were exposed to a $\mathrm{Ca}^{2+}$-free medium containing $3 \mathrm{mM}$ EGTA $(7-8.5 \mathrm{~min})$, and permeabilized with $0.5 \%$ Triton X-100 in the same medium (8.5-12 $\mathrm{min})$. At the end of each experiment, cells were superfused with a $\mathrm{Ca}^{2+}$-rich hypotonic medium $\left(10 \mathrm{mM} \mathrm{CaCl}_{2}\right.$ in $\left.\mathrm{H}_{2} \mathrm{O}\right)$. Photons emitted as a result of $\mathrm{Ca}^{2+}$ binding to charged aequorin were continuously detected by a photon-counting tube (Type H3460-04, Hamamatsu Photonics, Japan) that was positioned about $2 \mathrm{~cm}$ above the cells. Light impulses were pre-scaled and counted with a PC-based 32-bit counter/timer board (PCI-6601, National Instruments Corporation, Austin, TX, USA). The number of impulses occurring during a $1 \mathrm{sec}$ time interval was monitored with custom-built software. The recorded aequorin luminescence data were calibrated offline into cytosolic $\mathrm{Ca}^{2+}\left(\left[\mathrm{Ca}^{2+}\right]_{\text {in }}\right)$ values using the following equation: $\left[\mathrm{Ca}^{2+}\right]_{\text {in }}=\left(\left(L / L_{\max }\right)^{1 / 3}\right.$ $+\left[118\left(L / L_{\max }\right)^{1 / 3}-1\right) /\left(7 \times 10^{6}-\left[7 \times 10^{6}\left(L / L_{\max }\right)^{1 / 3)}\right]\right)$, where $L$ is the luminescence intensity at any time point and $L_{\max }$ is the integrated luminescence. The experiment was repeated three times.

\subsection{Vacuolar $p H$ Measurements}

The measurements were performed according to Diakov et al., with some modifications [69]. Briefly, WT S. cerevisiae BY4742 was grown overnight in $50 \mathrm{~mL} \mathrm{SD}_{\mathrm{HLLU}}$ containing $50 \mathrm{mM}$ MES to OD 2.0. The cells were then transferred to a $50 \mathrm{~mL}$ Falcon tube and centrifuged at $2061 \mathrm{~g}$ for $5 \mathrm{~min}$. The supernatant was discarded and the cells were resuspended in $250 \mu \mathrm{L}$ LoFlo $\mathrm{SD}_{\mathrm{HLLU}}$ medium containing $50 \mu \mathrm{M}$ 2'7'-Bis-(2-carboxyethyl)-5-(and 6)-carboxyfluorescein (BCECF-AM), then incubated at $30^{\circ} \mathrm{C}$ for $30 \mathrm{~min}$. While the cells were incubating, calibration buffers were prepared. These buffers contain cell-permeant ammonium acetate capable of collapsing $\mathrm{pH}$ gradients across multiple membranes, sodium azide and deoxyglucose to halt ATP production and inhibit the $\mathrm{H}^{+}$-pumps. The cells were then washed twice with the LoFlo medium and $20 \mu \mathrm{L}$ of the cells was transferred to each well of a multiwell plate containing $180 \mu \mathrm{L}$ medium or calibration buffer. The plates (Greiner, black Ref\# 655209) were then measured in a Fluoroskan apparatus with filters for BCECF-AM, alternately measuring at $\lambda_{\mathrm{ex}} 440$ and $485 \mathrm{~nm}$, and $\lambda_{\mathrm{em}}$ at $538 \mathrm{~nm}$. Baseline measurements were first taken for $1 \mathrm{~h}$ in the presence of calibration buffers covering a $\mathrm{pH}$ range of 4.5-7, then polygodial (final concentration 5, 15, and $45 \mu \mathrm{g} / \mathrm{mL}$ ) and DMSO were added in their respective wells, and the plate was further measured for $30 \mathrm{~min}$. To obtain a calibration curve, the ratio of fluorescence at 485 to $440 \mathrm{~nm}$ for each calibration buffer was calculated for each tested condition, then using the fluorescence ratios obtained with treated cells, vacuolar $\mathrm{pH}$ was calculated using the respective standard curves. The vacuolar $\mathrm{pH}$ was then plotted against time. The experiment was repeated twice.

Supplementary Materials: The following are available online at https:/ / www.mdpi.com/article/10 $.3390 /$ ijms22115756/s1. 
Author Contributions: Conceptualization, W.L., P.V.D., L.D., P.N.K., G.C., J.W.; Methodology, P.N.K., L.D., E.E., P.D., J.V.; Data analysis, P.N.K., L.D., E.E., G.C., J.W.; Resources, J.V., J.M., J.W., G.C., P.V.D., W.L.; Writing-Original draft preparation, P.N.K., W.L.; Writing-Reviewing and Editing, P.N.K., L.D., E.E., P.D., J.M., P.V.D., W.L., G.C., J.W. All authors have read and agreed to the published version of the manuscript.

Funding: The authors acknowledge funding from the Fund for Scientific Research Flanders research community on biofilms (WO.009.16N) to Patrick Van Dijck, the Interfaculty Council for Development Cooperation scholarship programme, KU Leuven to Purity N. Kipanga and a grant from KU Leuven, grant number C14/17/063 to Geert Callewaert, Joris Winderickx and Patrick Van Dijck.

Institutional Review Board Statement: Not applicable.

Informed Consent Statement: Not applicable.

Data Availability Statement: All data is presented in the Supplementary section.

Acknowledgments: We would like to thank the staff and colleagues at the laboratory of Molecular Cell Biology, KU Leuven for their support during the experiments and to Sujogya Kumar Panda for his efforts to ensure that the publication process of this manuscript was initiated.

Conflicts of Interest: The authors declare no conflict of interest.

\section{References}

1. Kubo, I.; Lee, Y.-W.; Pettei, M.; Pilkiewicz, F.; Nakanishi, K. Potent army worm antifeedants from the east African Warburgia plants. J. Chem. Soc. Chem. Commun. 1976, 1013-1014. [CrossRef]

2. Montenegro, I.; Pino, L.; Werner, E.; Madrid, A.; Espinoza, L.; Moreno, L.; Villena, J.; Cuellar, M. Comparative Study on the Larvicidal Activity of Drimane Sesquiterpenes and Nordrimane Compounds against Drosophila melanogaster til-til. Molecules 2013, 18, 4192-4208. [CrossRef]

3. Prota, N.; Bouwmeester, H.J.; Jongsma, M.A. Comparative antifeedant activities of polygodial and pyrethrins against whiteflies (Bemisia tabaci) and aphids (Myzus persicae). Pest Manag. Sci. 2014, 70, 682-688. [CrossRef]

4. Orme, I. Search for New Drugs for Treatment of Tuberculosis. Antimicrob. Agents Chemother. 2001, 45, 1943-1946. [CrossRef]

5. Robles-Kelly, C.; Rubio, J.; Thomas, M.; Sedán, C.; Martinez, R.; Olea, A.F.; Carrasco, H.; Taborga, L.; Silva-Moreno, E. Effect of drimenol and synthetic derivatives on growth and germination of Botrytis cinerea: Evaluation of possible mechanism of action. Pestic. Biochem. Physiol. 2017, 141, 50-56. [CrossRef]

6. Kipanga, P.N.; Liu, M.; Panda, S.K.; Mai, A.H.; Veryser, C.; Van Puyvelde, L.; De Borggraeve, W.; Van Dijck, P.; Matasyoh, J.; Luyten, W. Biofilm inhibiting properties of compounds from the leaves of Warburgia ugandensis Sprague subsp ugandensis against Candida and staphylococcal biofilms. J. Ethnopharmacol. 2020, 248, 112352. [CrossRef]

7. Kubo, I.; Fujita, K.-I.; Lee, S.H.; Ha, T.J. Antibacterial activity of polygodial. Phytother. Res. 2005, 19, 1013-1017. [CrossRef] [PubMed]

8. Matsumoto, T.; Tokuda, H. Antitumor-Promoting Activity of Sesquiterpene Isolated from an Herbal Spice. Basic Life Sci. 1990, 52, 423-427. [CrossRef]

9. Montenegro, I.J.; Del Corral, S.; Napal, G.N.D.; Carpinella, M.C.; Mellado, M.; Madrid, A.; Villena, J.; Palacios, S.M.; Cuellar, M.A. Antifeedant effect of polygodial and drimenol derivatives against Spodoptera frugiperda and Epilachna paenulata and quantitative structure-activity analysis. Pest Manag. Sci. 2018, 74, 1623-1629. [CrossRef]

10. Liu, M.; Kipanga, P.; Mai, A.H.; Dhondt, I.; Braeckman, B.P.; De Borggraeve, W.; Luyten, W. Bioassay-guided isolation of three anthelmintic compounds from Warburgia ugandensis Sprague subspecies ugandensis, and the mechanism of action of polygodial. Int. J. Parasitol. 2018, 48, 833-844. [CrossRef]

11. Ban, T.; Singh, I.P.; Etoh, H. Polygodial, a Potent Attachment-inhibiting Substance for the Blue Mussel, Mytilus edulis galloprovincialis from Tasmannia lanceolata. Biosci. Biotechnol. Biochem. 2000, 64, 2699-2701. [CrossRef] [PubMed]

12. Da Cunha, F.M.; Fröde, T.S.; Mendes, G.L.; Malheiros, A.; Filho, V.C.; Yunes, R.A.; Calixto, J.B. Additional evidence for the anti-inflammatory and anti-allergic properties of the sesquiterpene polygodial. Life Sci. 2001, 70, 159-169. [CrossRef]

13. Mendes, G.L.; Santos, A.R.; Malheiros, A.; Filho, V.C.; Yunes, R.A.; Calixto, J.B. Assessment of mechanisms involved in antinociception caused by sesquiterpene polygodial. J. Pharmacol. Exp. Ther. 2000, 292, 164-172. [PubMed]

14. Corrêa, D.S.; Tempone, A.G.; Reimão, J.Q.; Taniwaki, N.N.; Romoff, P.; Fávero, O.A.; Sartorelli, P.; Mecchi, M.C.; Lago, J.H.G. Antileishmanial and anti-trypanosomal potential of polygodial isolated from stem barks of Drimys brasiliensis Miers (Winteraceae). Parasitol. Res. 2011, 109, 231-236. [CrossRef] [PubMed]

15. Prota, N.; Mumm, R.; Bouwmeester, H.; Jongsma, M. Comparison of the chemical composition of three species of smartweed (genus Persicaria) with a focus on drimane sesquiterpenoids. Phytochemistry 2014, 108, 129-136. [CrossRef] [PubMed]

16. Muñoz-Concha, D.; Vogel, H.; Yunes, R.; Razmilic, I.; Bresciani, L.; Malheiros, A. Presence of polygodial and drimenol in Drimys populations from Chile. Biochem. Syst. Ecol. 2007, 35, 434-438. [CrossRef] 
17. Paul, V.J.; Seo, Y.; Cho, K.W.; Rho, J.-R.; Shin, J.; Bergquist, P.R. Sesquiterpenoids of the Drimane Class from a Sponge of the Genus Dysidea. J. Nat. Prod. 1997, 60, 1115-1120. [CrossRef]

18. Cimino, G.; De Rosa, S.; De Stefano, S.; Sodano, G.; Villani, G. Dorid Nudibranch Elaborates Its Own Chemical Defense. Science 1983, 219, 1237-1238. [CrossRef] [PubMed]

19. Jabra-Rizk, M.A.; Falkler, W.A.; Meiller, T.F. Fungal Biofilms and Drug Resistance. Emerg. Infect. Dis. 2004, 10, 14-19. [CrossRef]

20. Taniguchi, M.; Yano, Y.; Tada, E.; Ikenishi, K.; Oi, S.; Haraguchi, H.; Hashimoto, K.; Kubo, I. Mode of Action of Polygodial, an Antifungal Sesquiterpene Dialdehyde. Agric. Biol. Chem. 1988, 52, 1409-1414. [CrossRef]

21. Lunde, C.S.; Kubo, I. Effect of Polygodial on the Mitochondrial ATPase of Saccharomyces cerevisiae. Antimicrob. Agents Chemother 2000, 44, 1943-1953. [CrossRef]

22. Castelli, M.V.; Lodeyro, A.F.; Malheiros, A.; Zacchino, S.A.; Roveri, O.A. Inhibition of the mitochondrial ATP synthesis by polygodial, a naturally occurring dialdehyde unsaturated sesquiterpene. Biochem. Pharmacol. 2005, 70, 82-89. [CrossRef]

23. Kubo, I.; Fujita, K.; Lee, S.H. Antifungal Mechanism of Polygodial. J. Agric. Food Chem. 2001, 49, 1607-1611. [CrossRef]

24. Machida, K.; Tanaka, T.; Taniguchi, M. Depletion of glutathione as a cause of the promotive effects of polygodial, a sesquiterpene on the production of reactive oxygen species in Saccharomyces cerevisiae. J. Biosci. Bioeng. 1999, 88, 526-530. [CrossRef]

25. Kondo, T.; Takaochi, Y.; Fujita, K.-I.; Yamaguchi, Y.; Ogita, A.; Tanaka, T. Vacuole Disruption as the Primary Fungicidal Mechanism of Action of Polygodial, a Sesquiterpene Dialdehyde. Planta Med. Int. Open 2016, 3, e72-e76. [CrossRef]

26. Giaever, G.; Nislow, C. The Yeast Deletion Collection: A Decade of Functional Genomics. Genetics 2014, 197, 451-465. [CrossRef]

27. Yeast Deletion Web Pages. Available online: http://www-sequence.stanford.edu/group/yeast_deletion_project/deletions3.html (accessed on 1 April 2021).

28. Demuyser, L.; Van Dijck, P. Can Saccharomyces cerevisiae keep up as a model system in fungal azole susceptibility research? Drug Resist. Updat. 2019, 42, 22-34. [CrossRef]

29. Jones, T.; Federspiel, N.A.; Chibana, H.; Dungan, J.; Kalman, S.; Magee, B.B.; Newport, G.; Thorstenson, Y.R.; Agabian, N.; Magee, P.T.; et al. The diploid genome sequence of Candida albicans. Proc. Natl. Acad. Sci. USA 2004, 101, 7329-7334. [CrossRef] [PubMed]

30. Saccharomyces Genome Database I SGD. Available online: https://www.yeastgenome.org/ (accessed on 16 May 2021).

31. Robinson, M.D.; Grigull, J.; Mohammad, N.; Hughes, T.R. FunSpec: A web-based cluster interpreter for yeast. BMC Bioinform. 2002, 3, 35. [CrossRef] [PubMed]

32. Szklarczyk, D.; Morris, J.H.; Cook, H.; Kuhn, M.; Wyder, S.; Simonovic, M.; Santos, A.; Doncheva, N.T.; Roth, A.; Bork, P.; et al. The STRING database in 2017: Quality-controlled protein-protein association networks, made broadly accessible. Nucleic Acids Res. 2017, 45, D362-D368. [CrossRef]

33. Nicastro, R.; Sardu, A.; Panchaud, N.; De Virgilio, C. The Architecture of the Rag GTPase Signaling Network. Biomolecules 2017, 7, 48. [CrossRef]

34. Seaman, M.N.J. Endosome sorting: GSE complex minds the Gap. Nat. Cell Biol. 2006, 8, 648-649. [CrossRef]

35. Gao, M.; Kaiser, C.A. A conserved GTPase-containing complex is required for intracellular sorting of the general amino-acid permease in yeast. Nat. Cell Biol. 2006, 8, 657-667. [CrossRef]

36. Ukai, H.; Araki, Y.; Kira, S.; Oikawa, Y.; May, A.I.; Noda, T. Gtr/Ego-independent TORC1 activation is achieved through a glutamine-sensitive interaction with Pib2 on the vacuolar membrane. PLoS Genet. 2018, 14, e1007334. [CrossRef]

37. MacGurn, J.A.; Hsu, P.-C.; Smolka, M.B.; Emr, S.D. TORC1 Regulates Endocytosis via Npr1-Mediated Phosphoinhibition of a Ubiquitin Ligase Adaptor. Cell 2011, 147, 1104-1117. [CrossRef]

38. Yabuki, Y.; Ikeda, A.; Araki, M.; Kajiwara, K.; Mizuta, K.; Funato, K. Sphingolipid/Pkh1/2-TORC1/Sch9 Signaling Regulates Ribosome Biogenesis in Tunicamycin-Induced Stress Response in Yeast. Genetics 2019, 212, 175-186. [CrossRef]

39. Swinnen, E.; Wilms, T.; Idkowiak-Baldys, J.; Smets, B.; De Snijder, P.; Accardo, S.; Ghillebert, R.; Thevissen, K.; Cammue, B.; De Vos, D.; et al. The protein kinase Sch9 is a key regulator of sphingolipid metabolism in Saccharomyces cerevisiae. Mol. Biol. Cell 2014, 25, 196-211. [CrossRef]

40. Lavoie, H.; Whiteway, M. Increased Respiration in the sch9 $\Delta$ Mutant Is Required for Increasing Chronological Life Span but Not Replicative Life Span. Eukaryot. Cell 2008, 7, 1127-1135. [CrossRef] [PubMed]

41. Hu, K.; Guo, S.; Yan, G.; Yuan, W.; Zheng, Y.; Jiang, Y. Ubiquitin regulates TORC1 in yeast Saccharomyces cerevisiae. Mol. Microbiol. 2016, 100, 303-314. [CrossRef]

42. Jiang, Y. Regulation of TORC1 by ubiquitin through non-covalent binding. Curr. Genet. 2016, 62, 553-555. [CrossRef]

43. Halachmi, D.; Eilam, Y. Calcium homeostasis in yeast cells exposed to high concentrations of calcium Roles of vacuolar $\mathrm{H}^{+}-\mathrm{ATPa}_{\mathrm{T}}$ and cellular ATP. FEBS Lett. 1993, 316, 73-78. [CrossRef]

44. Förster, C.; Kane, P.M. Cytosolic $\mathrm{Ca}^{2+}$ Homeostasis Is a Constitutive Function of the V-ATPase in Saccharomyces cerevisiae. J. Biol. Chem. 2000, 275, 38245-38253. [CrossRef] [PubMed]

45. Yano, Y.; Taniguchi, M.; Tanaka, T.; Oi, S.; Kubo, I. Protective Effects of $\mathrm{Ca}^{2+}$ on Cell Membrane Damage by Polygodial in Saccharomyces cerevisiae. Agric. Biol. Chem. 1991, 55, 603-604. [CrossRef]

46. Devasahayam, G.; Ritz, D.; Helliwell, S.B.; Burke, D.J.; Sturgill, T.W. Pmr1, a Golgi Ca ${ }^{2+} / \mathrm{Mn}^{2+}$-ATPase, is a regulator of the target of rapamycin (TOR) signaling pathway in yeast. Proc. Natl. Acad. Sci. USA 2006, 103, 17840-17845. [CrossRef] [PubMed]

47. Dechant, R.; Peter, M. Nutrient signals driving cell growth. Curr. Opin. Cell Biol. 2008, 20, 678-687. [CrossRef] 
48. Kellermayer, R.; Szigeti, R.; Kellermayer, M.; Miseta, A. The intracellular dissipation of cytosolic calcium following glucose re-addition to carbohydrate depleted Saccharomyces cerevisiae. FEBS Lett. 2004, 571, 55-60. [CrossRef]

49. D’Hooge, P.; Coun, C.; Van Eyck, V.; Faes, L.; Ghillebert, R.; Mariën, L.; Winderickx, J.; Callewaert, G. Ca ${ }^{2+}$ homeostasis in the budding yeast Saccharomyces cerevisiae: Impact of ER/Golgi Ca ${ }^{2+}$ storage. Cell Calcium 2015, 58, 226-235. [CrossRef]

50. Parsons, A.B.; Brost, R.L.; Ding, H.; Li, Z.; Zhang, C.; Sheikh, B.; Brown, G.W.; Kane, P.M.; Hughes, T.R.; Boone, C. Integration of chemical-genetic and genetic interaction data links bioactive compounds to cellular target pathways. Nat. Biotechnol. 2004, 22, 62-69. [CrossRef]

51. Kapitzky, L.; Beltrao, P.; Berens, T.J.; Gassner, N.; Zhou, C.; Wüster, A.; Wu, J.; Babu, M.M.; Elledge, S.J.; Toczyski, D.; et al. Cross-species chemogenomic profiling reveals evolutionarily conserved drug mode of action. Mol. Syst. Biol. 2010, 6. [CrossRef]

52. Kane, P.M. The Where, When, and How of Organelle Acidification by the Yeast Vacuolar H+-ATPase. Microbiol. Mol. Biol. Rev. 2006, 70, 177-191. [CrossRef] [PubMed]

53. Walker, M.E.; Nguyen, T.D.; Liccioli, T.; Schmid, F.; Kalatzis, N.; Sundstrom, J.F.; Gardner, J.M.; Jiranek, V. Genome-wide identification of the Fermentome; genes required for successful and timely completion of wine-like fermentation by Saccharomyces cerevisiae. BMC Genom. 2014, 15, 552. [CrossRef]

54. Klionsky, D.J.; Herman, P.K.; Scott, D. The Fungal Vacuole: Composition, Function, and Biogenesis. Microbiol. Rev. 1990, 54, 266-292. [CrossRef]

55. Mellman, I.; Fuchs, R.; Helenius, A. Acidification of the endocytic and exocytic pathways. Ann. Rev. Biochem. 1986, 55, 663-700. [CrossRef]

56. Patenaude, C.; Zhang, Y.; Cormack, B.; Köhler, J.; Rao, R. Essential Role for Vacuolar Acidification in Candida albicans Virulence. J. Biol. Chem. 2013, 288, 26256-26264. [CrossRef] [PubMed]

57. Kim, S.; Coulombe, P.A. Emerging role for the cytoskeleton as an organizer and regulator of translation. Nat. Rev. Mol. Cell Biol. 2010, 11, 75-81. [CrossRef]

58. Pérez-Sayáns, M.; Suárez-Peñaranda, J.M.; Barros-Angueira, F.; Diz, P.G.; Gándara-Rey, J.M.; García-García, A. An update in the structure, function, and regulation of V-ATPases: The role of the C subunit. Braz. J. Biol. 2012, 72, 189-198. [CrossRef] [PubMed]

59. Zhang, J.W.; Parra, K.J.; Liu, J.; Kane, P.M. Characterization of a Temperature-sensitive Yeast Vacuolar ATPase Mutant with Defects in Actin Distribution and Bud Morphology. J. Biol. Chem. 1998, 273, 18470-18480. [CrossRef] [PubMed]

60. Buschlen, S.; Amillet, J.-M.; Guiard, B.; Fournier, A.; Marcireau, C.; Bolotin-Fukuhara, M. The S. cerevisiae HAP Complex, a Key Regulator of Mitochondrial Function, Coordinates Nuclear and Mitochondrial Gene Expression. Comp. Funct. Genom. 2003, 4, 37-46. [CrossRef] [PubMed]

61. Thön, M.; Al Abdallah, Q.; Hortschansky, P.; Scharf, D.H.; Eisendle, M.; Haas, H.; Brakhage, A.A. The CCAAT-binding complex coordinates the oxidative stress response in eukaryotes. Nucleic Acids Res. 2009, 38, 1098-1113. [CrossRef]

62. Yang, X.; Zhang, W.; Wen, X.; Bulinski, P.J.; Chomchai, D.A.; Arines, F.M.; Liu, Y.-Y.; Sprenger, S.; Teis, D.; Klionsky, D.J.; et al. TORC1 regulates vacuole membrane composition through ubiquitin- and ESCRT-dependent microautophagy. J. Cell Biol. $2020,219$. [CrossRef]

63. Wilms, T.; Swinnen, E.; Eskes, E.; Dolz-Edo, L.; Uwineza, A.; Van Essche, R.; Rosseels, J.; Zabrocki, P.; Cameroni, E.; Franssens, V.; et al. The yeast protein kinase Sch9 adjusts V-ATPase assembly/disassembly to control $\mathrm{pH}$ homeostasis and longevity in response to glucose availability. PLoS Genet. 2017, 13, e1006835. [CrossRef]

64. Cebollero, E.; Reggiori, F. Regulation of autophagy in yeast Saccharomyces cerevisiae. Biochim. Biophys. Acta Mol. Cell Res. 2009, 1793, 1413-1421. [CrossRef]

65. Pan, Y.; Schroeder, E.A.; Ocampo, A.; Barrientos, A.; Shadel, G.S. Regulation of Yeast Chronological Life Span by TORC1 via Adaptive Mitochondrial ROS Signaling. Cell Metab. 2011, 13, 668-678. [CrossRef]

66. Pan, Y.; Shadel, G.S. Extension of chronological life span by reduced TOR signaling requires down-regulation of Sch9p and involves increased mitochondrial OXPHOS complex density. Aging 2009, 1, 131-145. [CrossRef]

67. Kwon, Y.-Y.; Kim, S.-S.; Lee, H.-J.; Sheen, S.-H.; Kim, K.H.; Lee, C.-K. Long-Living Budding Yeast Cell Subpopulation Induced by Ethanol/Acetate and Respiration. J. Gerontol. Ser. A Boil. Sci. Med Sci. 2020, 75, 1448-1456. [CrossRef] [PubMed]

68. Sherman, F. Getting started with yeast. Methods Enzym. 2002, 350, 3-41.

69. Diakov, T.T.; Tarsio, M.; Kane, P.M. Measurement of vacuolar and cytosolic pH in vivo in yeast cell suspensions. J. Vis. Exp. 2013, e50261. [CrossRef] [PubMed] 